\title{
COMPUTER-AIDED SYSTEM FOR MODELLING MACHINERY PROCUREMENT DUE-DATE PREDICTION IN PRODUCTION INDUSTRIES
}

\author{
Basil O. Akinnuli \\ Department of Mechanical Engineering \\ Federal University of Technology, Akure, Nigeria. \\ ifembola@yahoo.com; bakinnuli@futa.edu.ng \\ Samuel A. Oluwadare ${ }^{1}$ \\ Department of Computer Science \\ Federal University of Technology, Akure, Nigeria. \\ oluwadaresam@yahoo.com ${ }^{1}$
}

\begin{abstract}
Machinery procurement is carried out in both government and private sectors. One of the major criteria for the selection of vendors is their ability to meet the due-date of supply. Failure to meet the supply due-date will affect installation time, commissioning time, as well as start- up date negatively. The set target for the period will be difficult to meet and working overtime to recover the lost period will cause over-flogging of machine, increase in wear rate which can lead to the life-span reduction of the machine. To arrest this situation, a stochastic model was developed to predict machinery/equipment procurement flow time and set due-date for the supply of the machine by the vendor. The model utilized data on the procurement activities which were analysed based on optimistic, most likely and pessimistic time for each activity. The stochastic model used Project Evaluation and Review Techniques (PERT) for analysing these three time estimates from which expected time was predicted. The model accommodates procurement strategic decisions, flow chart development, data collection form, network analysis, activities paths determination and critical path identification. This research was able to develop a model for machinery procurement, develop computer software for implementing the model and validate the effectiveness of the model using an existing company as case
\end{abstract}


study. The expected completion time is 45 days, with variance of 2 days while the probability of supplying the machine in not more than 2 days is $86 \%$. This model will find application in small, medium and large scale industries in both developing and developed countries.

Keywords: Model development, Machinery procurement, Due-date prediction, Computer-aided system.

\section{INTRODUCTION}

Machinery purchase for installation, commissioning and operations start-up has a lot to do with time. Delay in time for procured machinery supply always affects these three activities. One of the main objectives of a purchasing manger in a business organization is to procure necessary items to support business operations but it is also highly imperative that the purchasing manager knows the exact time the procured machinery should be supplied (Sharma, 2008).

The supply due-date prediction methods for machinery procurement are brain storming, guessing and executive meetings (Lamar \& Dobler, 1983); (Bersatkas, 1998). In brainstorming, a group of selected people are charged with the task of determining the due-date that will be best suitable for supply of procured equipment. The guessing method is almost the same as brainstorming in concept but the major difference is that the purchasing manager is left to predict a due-date for the supply of the equipment by guessing based on factors such as the equipment depreciation and status. The executive meetings method involves the sitting together of all the board of directors and mangers of the company to determine when equipment could be purchased based on some factors like available funds, the amount of products that need to be procured and so on. The board will, after their meetings, decide when and how this equipment will be procured for the company.

These three common methods for supply due-date determination do fail in several occasions for lack of scientific backing for establishing, analysing and testing their performance. This study reviewed previous models for predicting due-dates in relation to their applicability in machinery supply due-date problems in developing economies, and consequently evolved a quantitative stochastic model which accounts for external factors as well as avoiding most of the limiting assumptions and constraints of previous models. The model also prescribes an effective data base system through which the present model could be effectively implemented. Karmarker (1987) and Smith, Dude and Blair, (1986) presented a rather extensive discussion of the role of the due- 
date assignment in the contract of master production scheduling. Also an industrial survey of the United States' companies using the Flexible Manufacturing System (FMS) indicated that meeting promised delivery dates, is the most desirable objective which a manager wants to achieve (Evans \& Minieka, 1992).

A comprehensive survey of work in job-shop flow-time prediction and duedate setting carried out by Cheng and Gupta (1989), and Robinson, Goa and Muggenborg (1993) identified various factors which influence due-date prediction. The factors were categorized into job characteristics, shop status and system characteristics. Also four basic analytical models were identified by Enns (1993). However, little or nothing was done concerning the equipment supply due-date prediction model. All the studies mentioned above focused on job shop and flow shop due- date prediction. The focus was on queues to job shop and machine utilization.

This study carried out a general overview of the procurement methods. It comprised activities involved in machinery supply due-date and identified a quantitative mathematical model that is fit for solving the stochastic problem. Also, in carrying out this research, a review of some models which may be applied was carried out. The models reviewed included probabilistic dynamic programming, Markov chains, simulation, queuing theory, Critical Path Method (CPM), and Project Evaluation and Review Technique (PERT). The dynamic programming approach uses the idea of recursion to solve a complex problem by breaking it into a series of interrelated (sequential) decision stages. The outcome of a decision at one stage affects the decision of each of the next stages (Sharma, 2008). This is not applicable to strategic decisions of machine procurement. For instance, before releasing an order for procurement, the purchaser may have a supplier already and therefore, there is no need for bidding. Dalela and Mansoor (2006) stated that simulation deals with experimenting on a model by trying alternative actions or parameters and comparing their consequences. As the complexity of a model increases, simulation seeks to replicate the uncertainty in the model and assess the model's response to events made to occur with a frequency characterized by pre-specified probabilities. The identified strategic decisions for machinery procurement for due-date supply prediction have nothing to do with experimentation. Hence, there is no need for simulation application in solving the problem.

The Critical Path Method is used for the modelling of projects involving activities of repetitive nature. It allows an explicit estimate of costs in addition to time. This technique was developed in connection with a project in which the duration of each activity is known with certainty. The duration of each 
activity in the machine-procurement process is not known with certainty and activities involved are not repetitive in nature and no cost is required (Taha, 2008). Therefore, CPM was found not to be ideal for solving this problem.

The Project Evaluation and Review Technique (PERT) which was adopted in this research makes use of three estimates to form a weighted average of the expected completion time of each activity based on probability distribution of completion times. It is basically a tool for planning and controlling time. It emphasizes completion of the task rather than the activities to be performed to reach to a particular event or task and is used for activities of non-repetitive nature. It helps in identifying the critical areas in a project so that necessary adjustments can be made to meet the scheduled completion date of the project. Hence, based on these qualities of PERT, it was adopted in this research to develop a model for predicting supply due-date for machinery procurement.

The strategic decisions or activities of machinery procurement were stated by (Akinnuli, 2009) and (Martand, 2006) as: recognition of needs, transmission of needs, investigation and selection of suppliers, preparation and issuing purchase order, acknowledgment of order by the vendor or supplier, order follow-up, shipping of machinery, receiving of machinery, machinery inspection, equipment auditing and closing of order. This study which was application-oriented deliberated on how PERT can be utilized to obtain a better estimate of the due-date setting for machinery or equipment-procurement supply based on the strategic decisions involved in machinery procurement. PERT allows a large amount of data to be presented in a well-organized diagram known as network from which both the executor and the customer can make joint decisions (Aderoba, 1995). These techniques help the management to plan the best possible use of resources to a given goal within the time and cost limitation (Charnes \& Cooper, 2007). It helps management to handle the uncertainties involved in the programme, and cut time required for routine decisions, but allow more time for critical decision-making (Gueret, Prince \& Sevanux 2002).

\section{MODEL DEVELOPMENT}

\section{Network Development}

The activities in machinery procurement which need close monitoring to complete them in time were enumerated. Each activity was defined as: (a) preceding activity (the activity which preceded it), (b) succeeding activity (the activity which followed) (c) concurrent activity (the activity that can be done concurrently). Estimation of time for the completion of each activity was also carried out. 
The estimation of time for the completion of each activity is important in network analysis. This was done using three possible assumptions:

1. Optimistic time $\left(\mathrm{t}_{\mathrm{a}}\right)$ : This occurs when execution goes extremely well.

2. Most likely time $\left(\mathrm{t}_{0}\right)$ : This occurs when execution is done under normal conditions.

3. Pessimistic time $\left(\mathrm{t}_{\mathrm{b}}\right)$ : This occurs when execution goes extremely poorly.

The ranges $\left(\mathrm{t}_{\mathrm{a}} \mathrm{t}_{\mathrm{b}}\right)$ enclose all possible estimates of the duration of an activity. The estimate $t_{m}$ lies somewhere in the range $\left(t_{a} t_{b}\right)$. In Beta-distribution the midpoint $\left(t_{a}+t_{b}\right) / 2$ is assumed to weigh half as much as the mostly likely point $t_{m}$. Thus the expected average of three time estimates, is computed as the arithmetic of $\left(\mathrm{t}_{\mathrm{a}}+\mathrm{t}_{\mathrm{b}}\right) / 2$ and $2 \mathrm{t}_{\mathrm{m}}$. That is the Expected time of an activity $\left(\mathrm{t}_{\mathrm{e}}\right)$

$$
\begin{aligned}
& =\frac{\left(t_{a}+t_{b}\right) / 2+2 t_{m}}{3}=\frac{t_{a}+4 t_{m}+t_{b}}{6} \\
& t_{e}=\left(t_{a}+4 t_{m}+t_{b}\right) / 6
\end{aligned}
$$

where $\mathrm{t}_{\mathrm{a}}=$ estimated time; $\mathrm{ta}=$ most optimistic time; $\mathrm{t}_{\mathrm{m}}=$ normal time; and $\mathrm{t}_{\mathrm{b}}$ $=$ most pessimistic time.

\section{Standard Deviation}

Standard deviation of the estimated time $\left(\mathrm{t}_{\mathrm{e}}\right)$ :

$$
\operatorname{Sd}\left(\mathrm{t}_{\mathrm{e}}\right)=\left(\mathrm{t}_{\mathrm{b}}-\mathrm{t}_{\mathrm{a}}\right) / 6
$$

Standard deviation of the time $t_{e}$ to complete the supply of the machinery or equipment

$$
\mathrm{Sd}\left(\mathrm{t}_{\mathrm{e}}\right)=\left(\mathrm{t}_{\mathrm{bl}}-\mathrm{t}_{\mathrm{al}}\right) / 6+\left(\mathrm{t}_{\mathrm{b}} 2-\mathrm{t}_{\mathrm{a} 2}\right) / 6+\ldots .+\left(\mathrm{t}_{\mathrm{bn}}-\mathrm{t}_{\mathrm{an}}\right) / 6
$$

Variance of activity time, $\mathrm{V}_{\mathrm{i}}^{2}=\left[\left(\mathrm{t}_{\mathrm{b}}-\mathrm{t}_{\mathrm{a}}\right) / 6\right]^{2}$

\section{Critical Path}

The critical path is vital for the successful control of the project because it provides information to the management on two things which are: (a) no slack time in any of the events on the path, any delay will cause a corresponding delay in the end-date of the project, unless the delay can be recovered during 
any of the down-stream events on the critical path; and (b) the event on this path are the most critical for the success of the project. Management must take a hard look at these events, in order to improve the total project. Also, if we want to reduce the total duration of a project we should be able to reduce the time taken by the activities on the critical path. The variance of the total critical path's duration is the sum of the variances of the critical path. Suppose $[\mathrm{Sd}]_{\mathrm{c}}$ is the standard deviation of the critical path then:

$$
[\mathrm{Sd}]_{\mathrm{c}}^{2}=\sum \mathrm{Vi}^{2} \text { and }[\mathrm{Sd}]_{\mathrm{c}}=\sqrt{\sum \mathrm{V}_{\mathrm{i}}^{2}}
$$

\section{Estimation of Procurement Completion Time}

The chance of completing the supply of the machinery in a desired time and the duration necessary for obtaining any desired probability of actually meeting the scheduled time can be calculated thus:

$$
\operatorname{Prob}\left[Z=\left(\mathrm{T}_{\mathrm{s}}-\mathrm{T}_{\mathrm{e}}\right) /[\mathrm{Sd}]_{\mathrm{c}}\right]
$$

where

$\mathrm{T}_{\mathrm{s}} \quad=$ the probability of completing the supply of the machine in (desired) time.

$\mathrm{T}_{\mathrm{e}} \quad=$ expected completion time for the supply of machine

$\mathrm{Z} \quad=$ number of standard deviations of the scheduled time (or desired completion time) lies away from the mean or expected date.

$[\mathrm{Sd}]_{\mathrm{c}}=$ standard deviation of the critical path.

The desired completion time of the machine supply can be calculated as:

$$
\mathrm{T}_{\mathrm{s}}=\mathrm{Z}[\mathrm{Sd}]_{\mathrm{c}}+\mathrm{T}_{\mathrm{e}}
$$

The estimated completion time obtained through this model not only reflects the critical path and its variance but also indicates the probability of completing the supply of the machinery within the estimated time.

\section{MODEL IMPLEMENTATION}

The implementation of the above stochastic application model, developed using PERT, ensures that the time duration for each strategic decision (activity) is no longer just a single time estimate (i.e decision-maker's best guess) but 
a random variable which is characterized by some probability distributionusually a $\beta$ (beta) distribution. The PERT model requires three time estimates for each activity. The machinery procurement strategic decisions were identified, the requisition cycle logic was developed, data collection form for activities and their three time estimates were developed, the network for the supply activities was developed, the critical path for the developed network was determined to compute the expected supply time $\left(\mathrm{t}_{\mathrm{e}}\right)$ and its variance as well as the probability of supplying machinery within the limit of the expected supply time.

\section{Machine Procurement Strategic Decision}

This study identified the strategic decision required for machinery procurement as:

- $\quad$ recognition of need for machinery

- $\quad$ transmission of the need

- $\quad$ investigation and selection of supplier

- $\quad$ preparation and issuing purchase order

- acknowledgement of order by supplier or vendor

- $\quad$ following up the supply order

- $\quad$ shipping of equipment machine

- $\quad$ receiving of equipment / machine

- machine / equipment inspection

- $\quad$ equipment auditing and

- closing the orders.

\section{Machinery Requisition Cycle Logic}

The stages of machinery requisition require time to accomplish them. Some of these stages can be combined and at times some may be avoided for instance, where there is a regular supplier of an equipment, verifying the certificate of proficiency of the company, the stage three (investigation and selection of suppliers) may not be required. The logic is as shown in Figure 1.

\section{Data Collection Form}

The form designed for data collection is as shown in Table 1 . The optimistic time $\left(\mathrm{t}_{\mathrm{a}}\right)$, pessimistic time $\left(\mathrm{t}_{\mathrm{b}}\right)$ and most likely time $\left(\mathrm{t}_{\mathrm{m}}\right)$ decision were not left to the requisitor only. Departments and unit heads made inputs in order to avoid disappointment. 


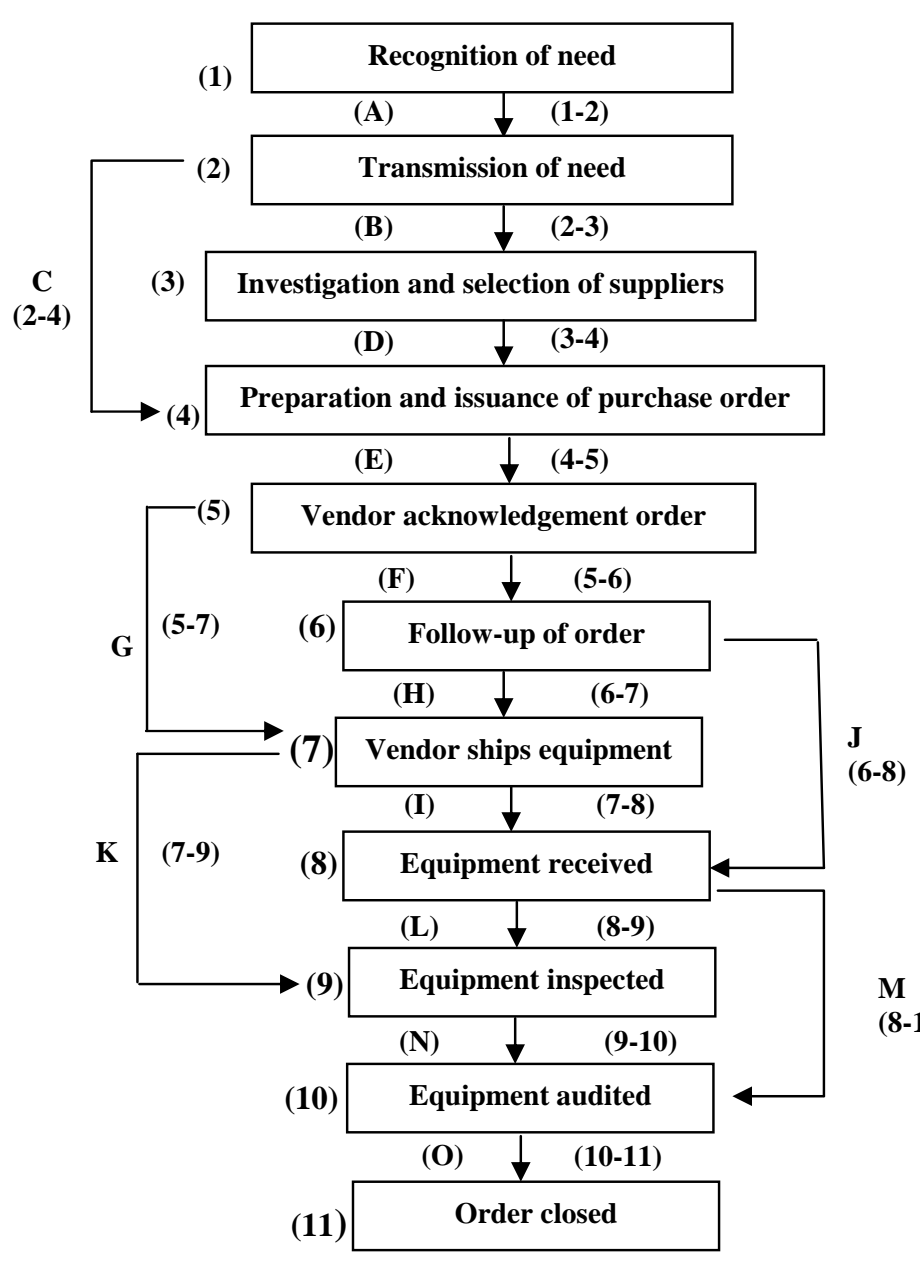

Figure 1. Machinery Requisition Cycle Logic Source: Akinnuli, 2009

\section{COMPUTER-AIDED SYSTEM}

The computer which was initially confined to laboratories and research institutes owing to its huge size, cost of acquisition, maintenance, lack of technical know-how to operate the machine, among others has found its application in almost every field of human endeavour. The computer which was originally designed to handle complex arithmetic calculations is now being used to solve problems in sciences, engineering, medicine, law, arts and humanities, and telecommunication. The advancement in electronic technology which has led to the drastic reduction in size with a corresponding 
increase in storage capacity and speed of processing of computers; and the growth of the computer software industry has led to the emergence of computer-aided systems (Oluwadare, 2000).

The Computer-Aided System for Modelling Machinery Procurement Due-date Prediction in Production Industries was developed using the model developed in the foregoing sections. The back-end which handles data storage is Microsoft Access 2003. The front-end is Visual Basic Application Programming Language version 6.0. Microsoft Access is adopted as the back-end due to its availability on most computers that run on Microsoft Windows Operating System platform and it is easy to use. The Visual Basic 6.0 which is adopted as the front-end is an event-driven programming language which has evolved as a result of the Graphical User Interface (GUI) provided by the Windows Operating System. Also, Visual Basic supports client/server computing which makes it possible to connect a single or more client machine to a multi-user server machine and share the processing load between the two. In this study, Visual Basic was used to develop a user-friendly, interactive and intelligent software package for modelling machine procurement due-date prediction.The top-down design adopted in the development and implementation of the computer-aided system enables the user to go through the menu and the dialogue sessions.

\section{Dialogue Sessions}

The first dialogue session begins when the user clicks the icon for the computeraided system on the Windows desktop. The session opens with the welcome and login screens as depicted in Figure 2 and Figure 3.

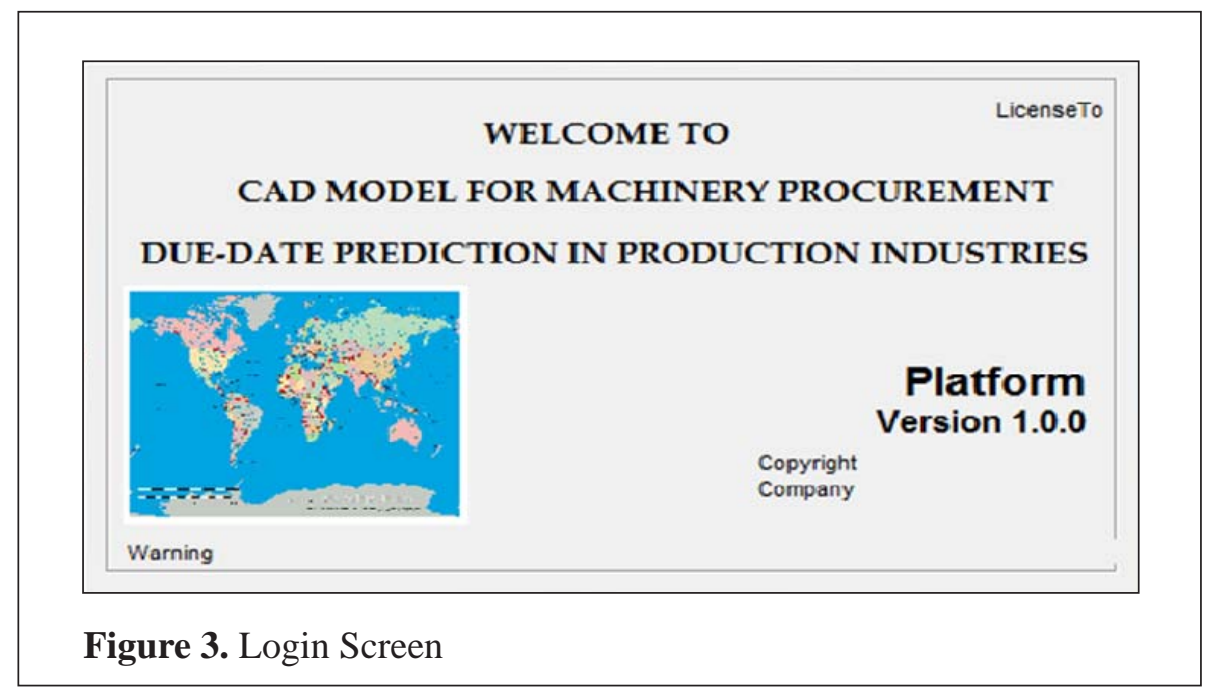


The login session ensures that only authorized users could have access to the system. The authorized user is granted access to the system if he supplies both the correct user name and password. Once the user is able to login successfully, he is taken to the Main menu depicted in Figure 4.

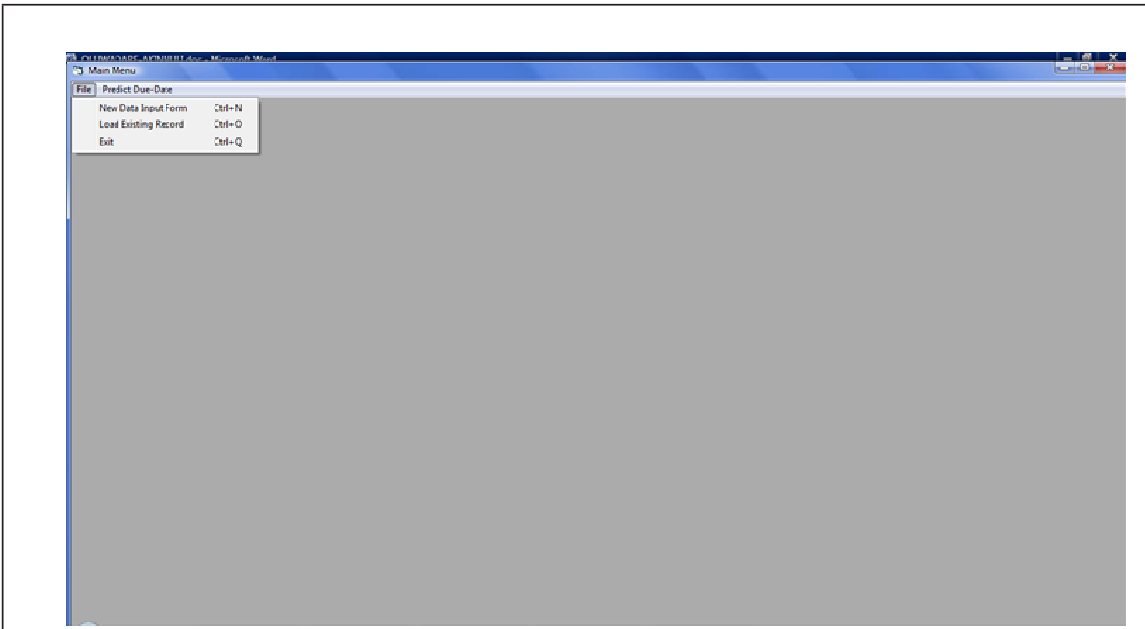

Figure 4. Main Menu

If the user clicks the File Menu he is taken to a sub-menu where he can choose to open a new data input form where he can enter new records for procurement due-date setting or load any existing record which might have been saved from a previous transaction.

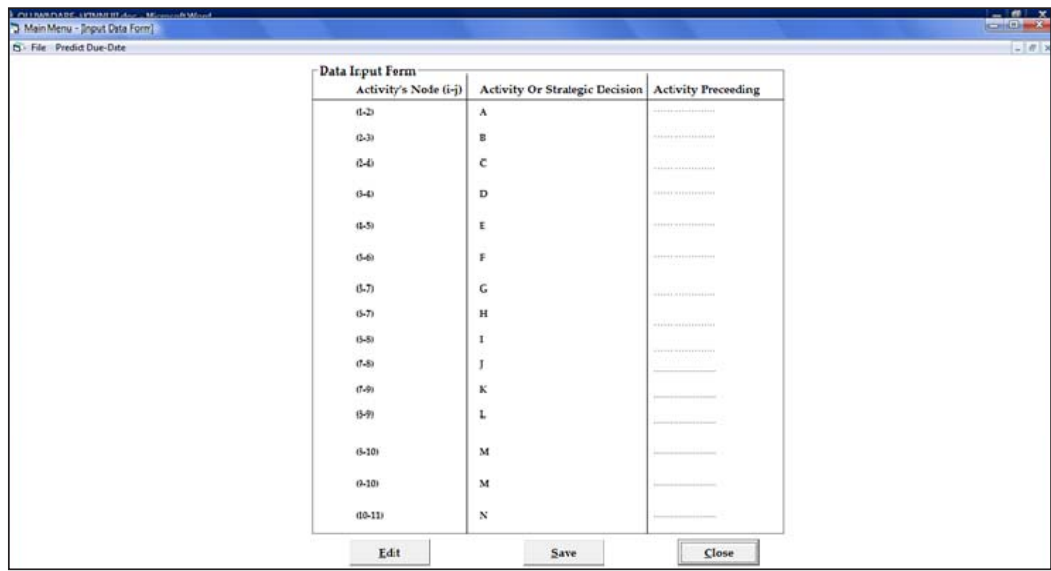

Figure 5. New Data Input Form 
Once the user clicks Edit he would be allowed to fill column three (activity preceding) after which he can save it to the computer hard disk by clicking the save button.

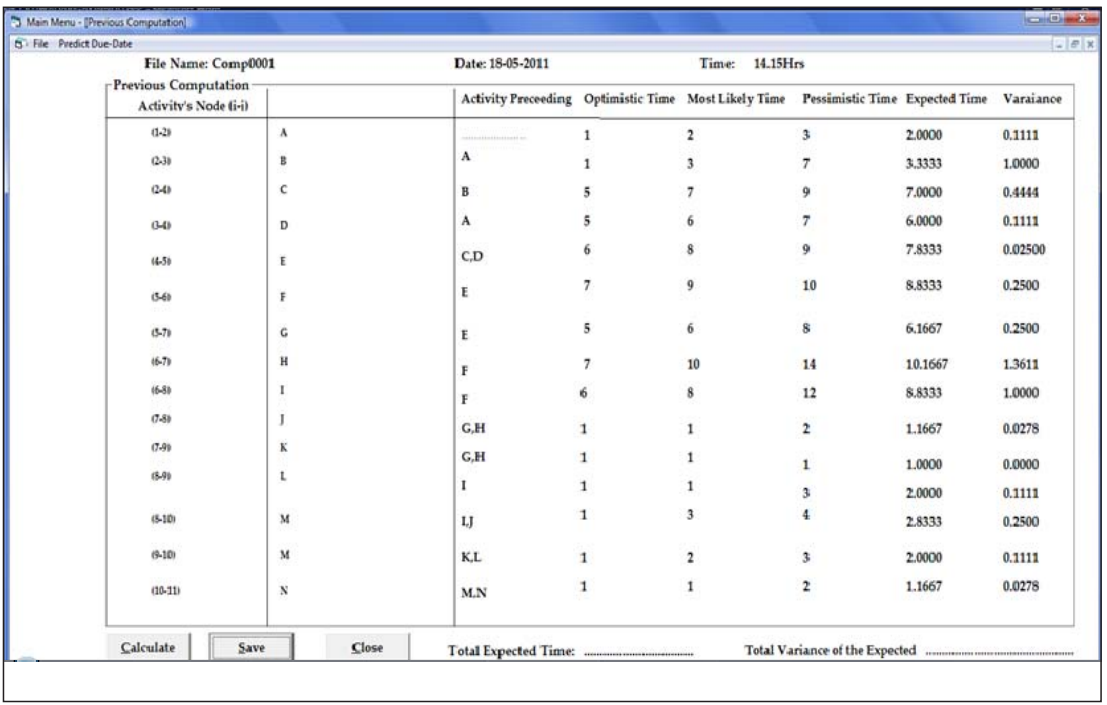

Figure 6. Existing Record

If the user clicks the load existing record he can load the record of any previous transaction that he wants to modify and then save it after updating. The option is useful when the user does not want to start from scratch but only wants to modify the data used for a particular previous session of due-date prediction.

\section{Predict Due-date}

This menu option enables the user to predict the due-date based on the data entered during the data input session in the File menu. The Predict Due-date menu has two options: From New Input and From Previous Computation. If the user selects the From New Input option the dialogue box depicted in Figure 7 is opened for him to supply the optimistic time, the most likely time and the pessimistic time for the various activities involved in the procurement of the machinery. Once this is done, the system automatically generates the corresponding figures for expected completion time and variance. If the user is satisfied, he can click the Calculate button in order to get the figure for the total expected completion time and total variance of the expected time. The user can also click the Save button in order to save the results for future use. 


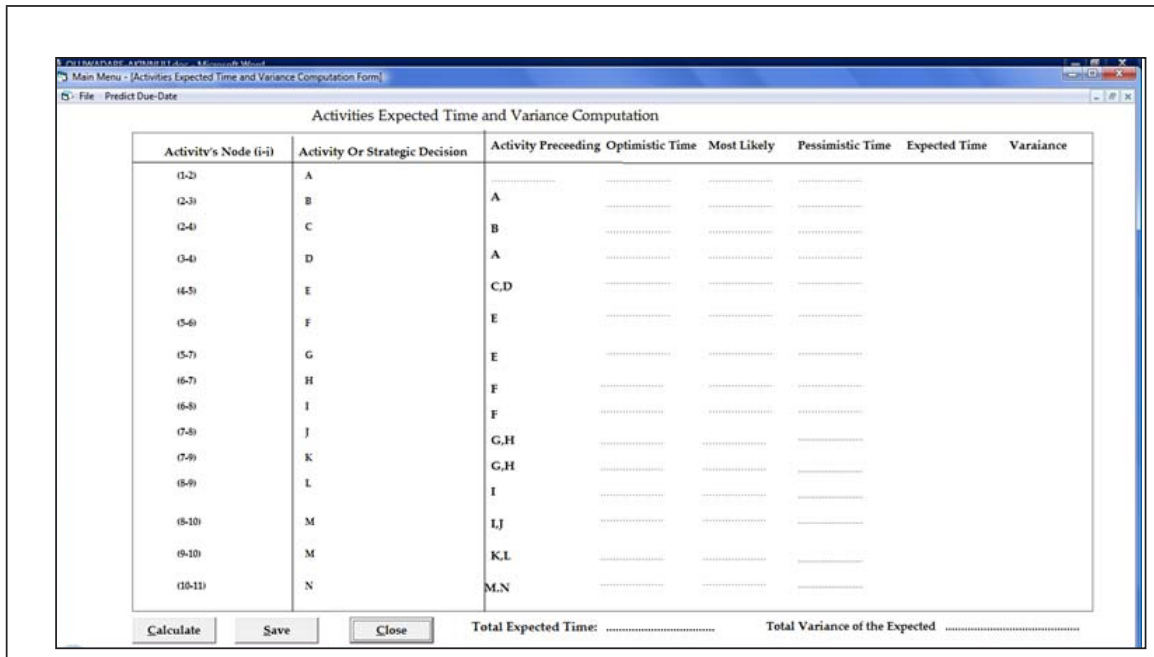

Figure 7. Activities Expected Time and Variance Computation Form

If the user clicks the From Previous Computation option, a form displaying the records of the previous computation similar to Figure 6 will be displayed. He can now edit and recalculate the total expected time and total variance of the expected time.

\section{Hardware Requirement}

In order to implement the computer-aided system, the following minimum hardware requirements are recommended: Minimum of Pentium M computer with 80GB hard disk, 500MB RAM, with Windows XP Operating System.

\section{CASE STUDY}

A cocoa processing company based in Akure, Nigeria, was used as a case study. The company found its cocoa-winnowing plant (which comprises the cleaning machine, the dryer and the winnowing machine) obsolete due to non-availability of spare parts high maintenance cost and technology advancement. These prompted the company to make a request for a new winnowing plant that put into consideration: economic values, engineering features and supply conditions. In order to overcome disappointment through guessing and brainstorming, the Federal University of Technology, Akure, Nigeria, was approached for the development of a computed-aided system for the procurement due-date prediction. The computer-aided model reported in this paper was developed to solve this problem. 


\section{RESULTS}

The results of the case study are presented in Tables 1 and 2. It is also depicted in the network diagram in Figure 8.

Table 1

Activities Expected Time and Variance Computation

\begin{tabular}{lccccccc}
\hline $\begin{array}{l}\text { Activity's } \\
\text { Node (i-j) }\end{array}$ & $\begin{array}{c}\text { Activity or } \\
\text { strategic } \\
\text { decision }\end{array}$ & $\begin{array}{c}\text { Activity } \\
\text { preceding }\end{array}$ & $\left(\mathrm{t}_{\mathrm{a}}\right)$ & $\left(\mathrm{t}_{\mathrm{m}}\right)$ & $\mathrm{t}_{\mathrm{b}}$ & $\mathrm{t}_{\mathrm{c}}=\left(\mathrm{t}_{\mathrm{a}}+4 \mathrm{t}_{\mathrm{m}}+\mathrm{t}_{\mathrm{b}}\right) / 6$ & $\mathrm{~V}=\left(\frac{\mathrm{t}_{\mathrm{b}}-\mathrm{t}_{\mathrm{a}}}{6}\right.$ \\
\hline$(1-2)$ & A & - & 1 & 2 & 3 & 2.0000 & 0.1111 \\
$(2-3)$ & B & A & 1 & 3 & 7 & 3.3333 & 1.0000 \\
$(2-4)$ & C & B & 5 & 7 & 9 & 7.0000 & 0.4444 \\
$(3-4)$ & D & A & 5 & 6 & 7 & 6.0000 & 0.1111 \\
$(4-5)$ & E & C,D & 6 & 8 & 9 & 7.8333 & 0.02500 \\
$(5-6)$ & F & E & 7 & 9 & 10 & 8.8333 & 0.2500 \\
$(5-7)$ & $\mathrm{G}$ & $\mathrm{E}$ & 5 & 6 & 8 & 6.1667 & 0.2500 \\
$(6-7)$ & $\mathrm{H}$ & $\mathrm{F}$ & 7 & 10 & 14 & 10.1667 & 1.3611 \\
$(6-8)$ & $\mathrm{I}$ & $\mathrm{F}$ & 6 & 8 & 12 & 8.8333 & 1.0000 \\
$(7-8)$ & $\mathrm{J}$ & $\mathrm{G}, \mathrm{H}$ & 1 & 1 & 2 & 1.1667 & 0.0278 \\
$(7-9)$ & $\mathrm{K}$ & $\mathrm{G}, \mathrm{H}$ & 1 & 1 & 1 & 1.0000 & 0.0000 \\
$(8-9)$ & $\mathrm{L}$ & $\mathrm{I}$ & 1 & 1 & 3 & 2.0000 & 0.1111 \\
$(8-10)$ & $\mathrm{M}$ & $\mathrm{I}, \mathrm{J}$ & 1 & 3 & 4 & 2.8333 & 0.2500 \\
$(9-10)$ & $\mathrm{M}$ & $\mathrm{K}, \mathrm{L}$ & 1 & 2 & 3 & 2.0000 & 0.1111 \\
$(10-11)$ & $\mathrm{N}$ & $\mathrm{M} . \mathrm{N}$ & 1 & 1 & 2 & 1.1667 & 0.0278 \\
\hline & & & & & & \\
\hline
\end{tabular}

The network diagram for the paths (activities) that lead to the supply of the machine as shown in Figure 8 is derived from Table 1. The paths indicated in bold arrows are the critical paths. The critical path is made up of the highest value of all the computed activity paths. This is usually chosen as the expected time (tc) for the supply of the machine. 


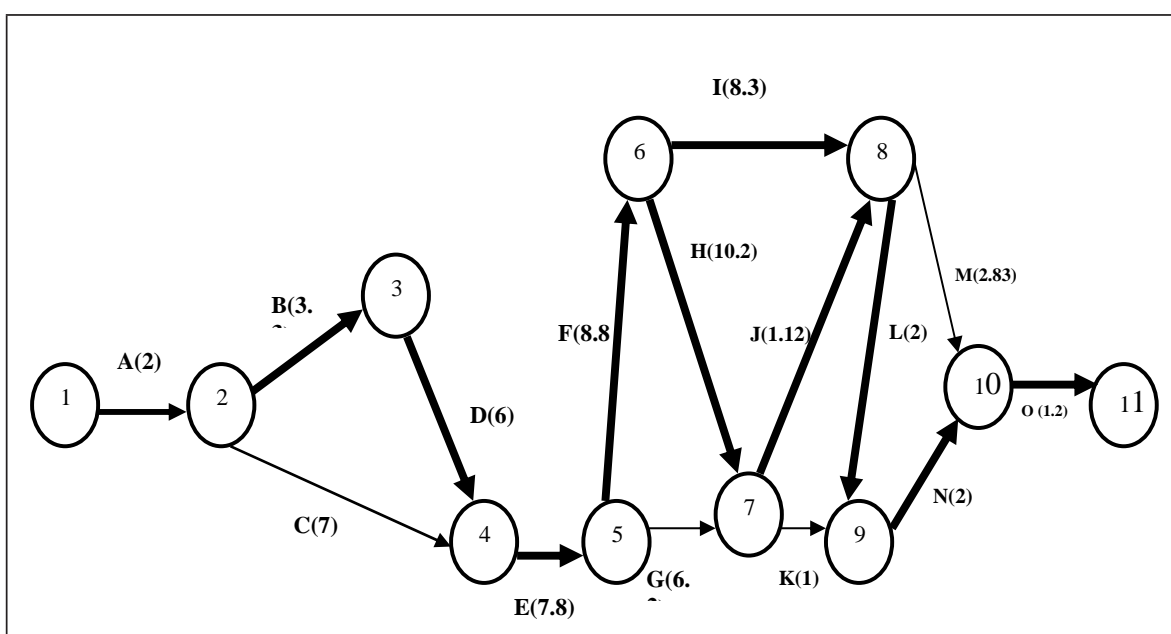

Figure 3. Network and Critical Path for Machinery Procurement Activities Source: Akinnuli, 2009

From the network diagram it is demonstrated that the expected completion time $\left(\mathrm{T}_{\mathrm{e}}\right.$ is 45 days, with a variance of 2 days while the probability of supplying the machine within the limit of 2 days is $86 \%$. These results are the benchmark available to determine every other result(s) from which conclusions can be drawn. When other scenarios are used, i.e. expected procurement time is less than or greater than 45 days, the probability as well as the variance will be affected positively or negatively depending on the value of increase or decrease in the expected procurement time. The range of expected procurement time which was less and greater than the bench-mark was taken as follows: (40, $41,42,43,44,(45), 46,47,48,49$ and (50) days. Given that variance index $=$ variance/expected time:

$$
\begin{aligned}
& \mathrm{V}_{i}=\mathrm{V}_{\mathrm{c}} / \mathrm{E}_{\mathrm{t}} \quad \mathrm{i}=0,1,2,3, \ldots \ldots \\
& \mathrm{V}_{i}=2 / 45=0.444
\end{aligned}
$$

where: $\mathrm{V}_{\mathrm{c}}=$ calculated variance, $\mathrm{V}_{i}=$ calculated variance index an $\mathrm{E}_{t}$ expected time.

Therefore for calculated " $\mathrm{Vc}$ " of any other expected time $\left(\mathrm{E}_{\mathrm{t}}\right) i$ where

$$
\mathrm{V}_{\mathrm{c}}=\mathrm{E}_{\mathrm{ti}} \mathrm{V}_{\mathrm{i}}
$$

For $\left(E_{t}\right)=40,41,42,43-\cdots, 50$. The summary of results are shown in Table 2. 
Table 2

Results Computed from Bench Mark

\begin{tabular}{cclccc}
\hline $\begin{array}{c}\left.\mathbb{E}_{\mathrm{t}}\right]_{i} \\
\text { (a) }\end{array}$ & $\begin{array}{c}V_{i} \\
(\mathbf{b})\end{array}$ & $\begin{array}{c}\mathbf{V}_{\mathbf{c}} \\
(\mathbf{c}=\mathbf{a x b})\end{array}$ & $\begin{array}{c}\mathbf{P}_{\mathbf{c}} \\
\mathbf{d}(\mathbf{\%})\end{array}$ & $\begin{array}{c}{[\mathbf{P}]} \\
\mathbf{e}=\mathbf{c ~ x ~ d} \mathbf{2} \mathbf{2}\end{array}$ & $\begin{array}{c}\text { Risk (R) } \\
\mathbf{f}=\mathbf{1 0 0}-\mathbf{e}\end{array}$ \\
\hline 40 & 0.0444 & 1.7776 & 86 & 76.437 & 23.563 \\
41 & 0.0444 & 1.82204 & 86 & 78.34779 & 21.652 \\
42 & 0.0444 & 1.8665 & 86 & 80.2595 & 19.740 \\
43 & 0.0444 & 1.9109 & 86 & 182.1687 & 17.831 \\
44 & 0.0444 & 1.99554 & 86 & 84.0822 & 15.918 \\
45 & 0.0444 & 1.9998 & 86 & 86.0000 & 14.000 \\
46 & 0.0444 & 2.0442 & 86 & 87.9023 & 12.0977 \\
47 & 0.0444 & 2.0887 & 86 & 89.8141 & 10.1859 \\
48 & 0.0444 & 2.1331 & 86 & 91.7233 & 8.2767 \\
49 & 0.0444 & 2.1776 & 86 & 93.6368 & 6.3632 \\
50 & 0.0444 & 2.222 & 86 & 95.546 & 4.454 \\
\hline
\end{tabular}

Where:

$$
\begin{array}{ll}
\left.{ }_{E_{t}}\right]_{\mathrm{I}} & =\text { Expected time for each activity (days) } \\
\mathrm{V}_{i} & =\text { Variance index }(0.0444) \text { for the bench-mark } \\
\mathrm{V}_{\mathrm{c}} & =\text { Calculated variance for each expected time (days) } \\
\mathrm{P}_{\mathrm{c}} & =\text { Probability for the bench- mark } 86 \% \text { or }(0.86) \\
{[\mathrm{P}]_{\mathrm{I}}} & =\text { Probability for each expected time }\left(\mathrm{E}_{\mathrm{t}}\right)_{i}
\end{array}
$$

Deduction: As expected the supply due date $\left[\mathrm{E}_{\mathrm{t}}\right]_{i}$ increases downward and so does the calculated variance $\mathrm{V}_{c}$ and their probability $[\mathrm{P}]_{I}$. The risk attached to each expected time is the reverse because as the expected time $\left[\mathrm{E}_{\mathrm{t}}\right]_{i}$ increases the risk reduces and vice versa.

\section{CONCLUSIONS}

This study reviewed the literature on due-date setting as it concerns machinery supply and concludes that most of the existing models will not find ready application either because they are not scientifically proved (guessing and brainstorming) or the analytical models available do not focus on machinery supply due-date setting but on job-shop due-date setting. 
The stochastic model developed has a database system. The sampling procedure and analysis are simple and tractable. This model will facilitate decision-making as per procurement of the industrial machinery due-date setting. The probability of meeting the due-date as well as the risk level involved could be easily ascertained. It will also make machinery installation, commissioning and start-up times reliable.

\section{REFERENCES}

Aderoba, A. A. (1995). Tools of engineering management engineering project management (1st ed.). Nigeria: Besade Nigeria Limited Ondo.

Akinnuli, B. O. (2009). Development of models for machinery evaluation in manufacturing industries (Unpublished doctoral dissertation). The Federal University of Technology, Akure.

Ersetkas, D. (1998). Network optimization continue and discrete models. Athena Scientific, Nashua. NH, 67-69.

Cheng, T. C. E., \& Gupta, M. C. (1994). Survey of scheduling research involving due-date determination decisions'. European Journal of Operation Research, 38, 156-166.

Chang, T. C. E., \& Gupta, M. C. (1989). A study of factors affecting duedate predictability in a simulated dynamic job-shop. Journal of Manufacturing System, 13(6), 393-405.

Enns, S. T. (1992). Job shop flow-time prediction and tardiness control using, queuing analysis. International Journal of Production Research, 31 (9), 2045-2057.

Evan, J. R., \& Miniaka, E, (1992). Optimization algorithms for networks and graphs (2nd ed.). New York: Marcel Dekker.

Glover, F., Khingman, D., \& Philips, N. (1992). Network models and their applications in practice: New York: John Wiley \& Son.

Gueret, C., Prince, C., \& Sevanux, M. (2002). Applications of optimization with express-MP. Translated and revised by Susanne Heipke, Dash Optimization. London, 265-269. 
Karmarker, U. S (1987). Lot sizes, lead times, and in process inventories. Management Science' 33, 409-411.

Lamar, L., \& Dobler, D. W. (1983). Fundamentals of purchasing and materials management (3rd ed.). TATA MC. New Delhi: Graw Hill.

Martand, T. (2006). Industrial engineering and production management (2nd ed.). New Delhi: S. Chan.

Oluwadare, S. A. (2000). Computer-aided system for monitoring and evaluation of software development, operations and maintenance (Unpublished master's thesis). The Federal University of Technology, Akure, Nigeria.

Robinson, E. W., Goa, L., \& Muggenborg, S. (1993). Designing and integrated distribution system and down brands. Inc. Interfaces, 23(3), 107-117.

Sharma, J. K. (2008). Operation research theory and application (3rd ed.). New Delhi: India, Macmillan.

Smith, M. L., Dude, K. R., \& Blair, E. L. (1986). Characteristics of US flexible manufacturing system. In a survey Stecke and Suri (Eds), Flexible manufacturing systems. Amsterdam: Elsevier.

Taha, H. A. (2008). Operations research: An introduction (8th ed.). New Delhi: PHI Learning. 